\title{
Peace and honour
}

\section{The 2005 Nobel Peace Prize is a timely reminder of the good work done by the International Atomic Energy Agency and its director, Mohamed ElBaradei.}

$\mathrm{R}$ ecipients of the Nobel Peace Prize have not always met with universal approval, but the 2005 award to the International Atomic Energy Agency (IAEA) and its director, Mohamed ElBaradei, is both timely and appropriate.

Since it was set up within the United Nations in 1957, the IAEA has sought to slow the spread of nuclear weapons while allowing nations access to the peaceful use of nuclear technology. In the past few years, it has played an important role in verifying adherence to the Nuclear Non-Proliferation Treaty and restricting the spread of weapons technology. But with greater support from governments, it could do far more.

At a time when nuclear non-proliferation faces several acute challenges, the IAEA has managed to maintain its reputation as an impartial arbiter on nuclear issues. This is due in large part to the performance of ElBaradei, an Egyptian-born lawyer and diplomat, who has fought fiercely to maintain the agency's independence. One of his finest hours was in 2001, when he refused to confirm the Bush administration's contention that the Iraqi government had restarted its nuclear programme. In a testament to his diplomatic acumen, ElBaradei survived a subsequent US attempt to oust him from his directorship, and was reappointed to a third term by unanimous consent in June.

But the IAEA could do a lot more to confront nuclear threats if the national governments whose contributions keep it going allowed it funding and authority equal to its task.

First and foremost, the IAEA should be given wider powers to enforce the non-proliferation treaty (see Nature 435, 132; 2005). Under a proposed modification to the treaty, the IAEA's powers to inspect facilities would be strengthened and its remit to analyse nations' nudear intentions widened. Most parties to the treaty have implemented the additional protocol, but others - including the United States, Russia and Iran - have yet to do so.

Second, the agency should be given more support to help it secure nudear facilities and recover missing nuclear materials. At present, the agency's directorate for safety and security, which oversees such activities, has a budget of just US\$22.4 million per year - a meagre amount for such a complex and important task. Given the frequency of nuclear materials trafficking, nations should be prepared to sharply increase this budget. The agency is not meant to be a nuclear police force, but more funding would allow it to help member states ensure the security of their own nuclear materials, while continuing recovery operations in the countries in the former Soviet Union, which are riddled with abandoned sources.

Finally, nations should give serious consideration to ElBaradei's proposal that the world's nuclear-fuel stockpiles be put under the stewardship of his agency. Such a proposal may sound radical, but if implemented carefully, it could go a long way towards ensuring that most of the world's nuclear material is accounted for. More importantly, placing the distribution of nuclear fuel
"Nations should give serious consideration to ElBaradei's proposal that the world's nuclear-fuel stockpiles be put under the stewardship of his agency." under an international authority would discredit the claims of countries such as Iran and Brazil that they must develop dual-use, nuclear fuel technology to meet their domestic energy needs.

All these steps will require the commitment of the IAEA's member states. Unfortunately, the most important players are unable to agree on how to move the agency forward. The award of this year's peace prize should serve as a wake-up call for them.

than 80 countries to take the plan forward, and then sat down with the heads of the vaccine industry. The Senate has approved $\$ 3.9$ billion to fight avian flu, with $\$ 3$ billion of it going on a US stockpile of antivirals. And Michael Leavitt, the health secretary, has gone on a ten-day trip to meet officials in affected countries in southeast Asia.

But behind this activity, there are disconcerting gaps between the official discourse and reality. US officials have correctly identified promptly stamping out outbreaks as a top priority, emphasizing the need for affected countries to share data and samples. This is an important issue, but what can the coalition do if China and Vietnam, for example, refuse to share data? And even more urgently required are funds to build surveillance capacity in vulnerable countries, and to eradicate the disease in livestock.

The United Nations' Food and Agriculture Organization estimated in February that a minimum of $\$ 100$ million is needed to begin tackling the problem effectively. But so far, a few countries 